\title{
Describing Relational Thinking Process of Junior High School Students with High Capability
}

\author{
Niyan Fajar Kusuma, Sri Subanti, and Budi Usodo \\ Postgraduate School of Mathematics Education Sebelas Maret University \\ Surakarta, Indonesia \\ niyankusuma@gmail.com
}

\begin{abstract}
Learning mathematics in Junior High School is transition from arithmetic to algebra. In algebra, students must develop a relational view of the symbol if they are to make any sense of more complicated equations with operations on both sides of the equal sign. The term relational thinking is used here to encompass more than a relational understanding of the equal sign. It is important to discuss students' relational thinking process when solving unknown number on mathematic sentences, so it can prevents students' misconception about the meaning of equal sign. Descriptive method was used in this study, involving five students of Junior High School in Boyolali with high capability in mathematics. The result of this study showed that students had a deep understanding about the meaning of equal sign. They knew that the equal sign as symbol of mathematical equivalence. Therefore, they were able to solve the mathematic sentences with relational thinking strategies rather than arithmetic procedures.
\end{abstract}

\section{Keywords-relational thinking, equivalence, equal sign}

\section{INTRODUCTION}

Learning mathematics in junior high school is basically a transition from learning arithmetic to algebra. Algebra is a very important branch of mathematics in shaping mathematical character of children, because with algebra, children are trained to think numerically, critically, creatively, reasonably, and think abstractly. Arithmetic and algebra are related to numbers and count operations, but algebra focuses more on the relationship between numbers and uses symbolic language or often called variables [11]. Algebra can be understood easily if students have gained initial knowledge that is regarding arithmetic.

The equal sign in an equation is defined as a symbol expressing the relation or equivalence of two equations. However, students often misinterpret the equal sign as an operational rather than as a symbol of mathematical equivalence [1] [5] [6] [7]. It could make students finding difficulties when they are being asked to solve problems that related to algebra material. For example, when students are requested to solve equations $5+3 x=14$, students tend to move the segment which is moving the number 5 to the right side, so that the equation become $3 x=14-5$, then the students move the number 3 to the right side, thus it becomes $x=\frac{9}{3}$ without knowing the reason why students should do so. Kieran in Aydin [2] claims that the student who views the right- hand side of an equation as an answer and solves the problem by moving the segment, lacks of understanding concerning equality between the right and left sides of the equation.

Stephens [7] also states that in learning algebra, students must develop a relational view concerning symbols if the student wishes to understand more complicated equations with operations on both sides that using equal sign, as an example; $5 x-7=2 x-11$. Furthermore, students who can show clear evidence of relational strategies to solve mathematical sentences are doing better in completing symbolic sentences than students who only use computational methods to solve mathematical sentences [8]. The results show that students whothink relationally tend to succeed with sentences involving symbols and numerical terms rather than students who only think arithmetically in a sentence of numbers.

Based on the research that conducted by Stephens \& Riberio [9], it was found that in Brazil, when seventh and eighth graders were required to complete a mathematical sentence using four arithmetic operations, most students used computational methods. However, when students were asked to show their relational thinking, most of them also didthe same, even though much support were needed in that regard.

The research result that carried out by Baiduri [3] showed that the relational thinking processes of male and female students with high capability when facing mathematical problems are that they understood the problems and answered the questions in the problems. The relations made by the male students were richer than those by female students. At the end of his article, Baiduri advices readers to study the relational thinking process of elementary school students with low or average capability in mathematics or secondary high school or university and at stage of solving mathematical problem developed by Polya, so that further study is needed to be done. Nevertheless, in this research mathematical problem is not developed based on Polya.

\section{THEORETICAL FRAMEWORK}

Stephens [7] argues that mathematics education literatures are full of information which explain that elementary and high school students have difficulties with algebra. The difficulties that are experienced by the students concerning more on solving algebraic equations, interpreting symbolic signs, and 
understanding aspects related to algebra. Some of these difficulties can be expected happened because of a lack of understanding regarding concept of algebra, especially about equality in a certain equation.

Meanwhile, equality is important in mathematics, especially on the equal sign as in the context of equations. Several studies have shown that elementary school students often see, the equal sign is the same as a command to obtain a result rather than a symbol for equality of a mathematical sentence. This inappropriate interpretation of equal sign, in a finite context, is called "misconception", because it does not indicate a general understanding of symbols that expressing equality between two equations.

Stephens [8] states that relational thinking is a strategy to solve problems related to numbers by giving understanding towards relationship between the numbers. For example, to complete $47+25$, it can be transformed into $50+22$ by adding 3 to number 47 and subtracting 3 from number 25 . Stephens also states that solving an equation will succeed by using relational thinking especially the existence of deep understanding of similarity.

Relational thinking can be illustrated by giving example of a mathematical sentence, as an instance suppose given a mathematical sentence $8+4=\square+5$. Students can find the correct number to put into the box by summing 8 and 4 , then find out what number that supposed to be added to 5 , so that, number 12 is obtained. That solution is a proper solution to the problem associated with the equal sign which is the expression of a relation. Although the solution is true, but it still relies on predetermined calculations. Students who really understand the equation will realize that 5 is one more than 4 , so the number in the box is one less than 8 . That student uses the relationship in solving the problem which becomes $8+4=(7+1)+4=$ $7+(1+4)=7+5$.

Furthermore, Knuth et al in Stephens [7] show evidence of a link between primary school students' understanding of equal sign and their ability to recognize equality of equations. The results explain that students who define equal sign as symbols of equality in mathematical sentences, not only know that the mathematical sentences $2 \times \square+15=31$ and $2 \times \square+$ $15-9=31-9$ have the same solution, but also can explain that the two mathematical sentences have the same solution without completing the two mathematical sentences.

In line with that opinion, Carpenter [4] states that relational thinking involves using fundamental properties of number and operations to transform mathematical expressions rather than simply calculating an answer following a prescribed sequence of procedures. Students with relational thinking not only count the correct answers, but also can explain the mathematical expression to obtain the answer by using the nature of numbers and operations.

The benefits of relational thinking according to experts in learning mathematics in schools, are mention bellow:
1. Students can understand the meaning of equal sign as well as the structure in a mathematical sentence or equation [5].

2. Students can complete both mathematical sentences and equation better compared with students who use computational methods [8].

3. Students can understand the equality between the right and the left side on a mathematical sentences or equation, so that when the students are asked to complete an equation, the students do not move the segment but they have a view on the equivalence of the two equations [2].

\section{RESEARCH METHOD}

This Research used qualitative method with descriptive research type. The strategy that chosen is a case study strategy. This research was conducted at one of junior high school in Boyolali Central Java Province, Indonesia. There are 5 students that used as participants. The subjects of the study that being chosen were students of grade 7 with high capability in mathematics also relatively the same scores and with good communication skills. They are SB, SD, SP, ST, and SN.This qualitative study was carried out in the following four procedures. Firstly, researchers collected data from individual written test. Secondly, we collected data from individual interview. Thirdly, we analyzed data by comparing data that were collected from individual written test with data that collected from individual interview. Fourthly, we made conclusions.

\section{RESUlT AND DisCUSSION}

Based on data analyzing, we classify the results into two sections. The sections are seen from students' test result and students' interview data results. There were eight questions given by researcher. It aimed for identifying students' relational thinking process that given by researcher. Students' relational thinking process will be described in the following section.

Based on students' responses, five students had a deep understanding about the meaning of equal sign. They knew that the equal sign as symbol of mathematical equivalence. Then, all of them showed clear evidence of using relational thinking to obtain a correct result. However, it will take one example of the results of the interview and answer of five students i.e student SB.

\section{Question 1:}

$6,7+13,6=7+a$

Determine the value of $a$ !

Answer:

Fig. 1 below is student SB answer to question 1 . 


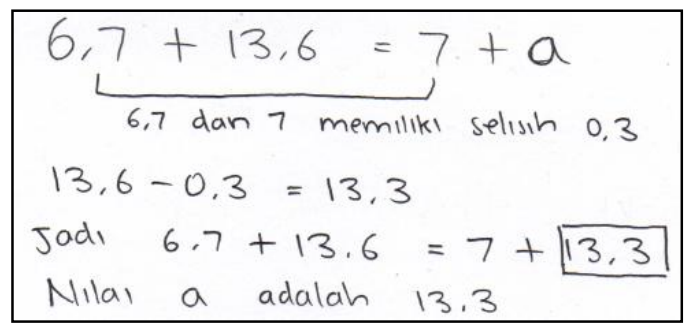

Fig. 1. The student SB answer of question 1

Fig. 1, it was assumed that student SB was aware of the relationship between number 6,7 on the left side with number 7 on the right side. Next, student SB calculate the difference of both numbers is 0.3 . From the result of the difference between two numbers, student SB used it to obtain the number on the right side that was not yet known. For more details, the result of the researcher's interview with the student SB on the first question are listed in Table I below:

TABLE I. RESULT OF INTERVIEW WITH STUDENT SB OF QUESTION 1

\begin{tabular}{|l|l|}
\hline \multicolumn{1}{|c|}{ Code } & \multicolumn{1}{c|}{ Interview Result } \\
\hline $\mathrm{R}$ & "Just look at the sheet on you, what is the value of a? " \\
\hline SB1 & "This is mom. The value of a is 13,3." \\
\hline R & "How do you get the value of a?" \\
\hline SB2 & $\begin{array}{l}\text { "Left side has value } 6,7+13,6=20,3 \text {. In order to make the } \\
\text { right side worth the same with left side, then it needs to be } \\
\text { added with number } 0,3 . "\end{array}$ \\
\hline R & "How you got number 0.3?" \\
\hline SB3 & "Number 0,3 is subtraction from 13,6" \\
\hline
\end{tabular}

Based on interview result with student $\mathrm{SB}$, it was found that student SB considers that there was a similarity between the right side and the left side. Furthermore, student SB explained that, if on the left side there was a number of $6.7+13.6=20.3$, then on the right side it should also be worth the same, that was 20.3. In order for the right side to have the same value as the left side, student SB obtained a relationship between numbers 6.7 with 7 , so that the difference of 0.3 from the two numbers was obtained. Furthermore, student SB subtracted number 13.6 that existed on the left with number 0.3 thus the value of "a" was 13.3.

Question 2:

$41,8-27,9=b-28$

Determine the value of $b$ !

Answer:

Fig. 2 below is student SB answer to question 2 .

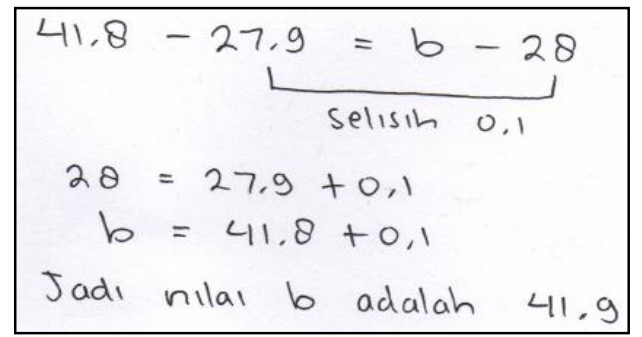

Fig. 2. The student SB answer of question 2
Fig. 2 show that allegedly student SB reconcile the connection between number 27.9 on the left with number 28 on the right side. Next student SB calculate the difference of both numbers, which was 0.1 . From the result of the difference between the two numbers, student SB uses it to obtain the number on the right side that is not yet known. For more details, the result of the researcher's interview with the student SB on the first question are listed in Table II below:

TABLE II. RESUlt OF INTERVIEW WITH STUDENT SB OF QUESTION II

\begin{tabular}{|c|c|}
\hline Code & $\begin{array}{l}\text { Interview Result } \\
\end{array}$ \\
\hline $\mathrm{R}$ & "Just look at the sheet on you, what is the value of b?" \\
\hline SB1 & "This is mom. The value of a is $41,9 . "$ \\
\hline $\mathrm{R}$ & "How do you get the value of b?" \\
\hline SB2 & $\begin{array}{l}\text { "It was different with number } 1, \text { I used little bit different } \\
\text { solution" }\end{array}$ \\
\hline $\mathrm{R}$ & "Show me how you do it!" \\
\hline SB3 & $\begin{array}{l}\text { "28=27,9+0,1 } \\
41,9=41,8+0,1 \\
\text { Like this ma'am" }\end{array}$ \\
\hline $\mathrm{R}$ & "please, explain it once more" \\
\hline SB4 & $\begin{array}{l}\text { "to get number } 28 \text { on the right side, it could be done by adding } \\
\text { number } 27.9 \text { on the left side with number } 0.1 \text {. Next, to obtain } \\
\text { the value of unknown number on the right side, is by also } \\
\text { adding number } 41,8 \text { on the left side with } 0,1 . " \text {. }\end{array}$ \\
\hline $\mathrm{R}$ & "How do you get number 0,1 ?" \\
\hline SB5 & $\begin{array}{l}\text { "Number } 0,1 \text { is obtained from the difference between numbers } \\
\text { in right and left side." }\end{array}$ \\
\hline
\end{tabular}

Based on interview result with student $\mathrm{SB}$, it was found that student SB used the same way with question number 1 to solve question number 2. Student SB obtained relationship between numbers on the left side with numbers on the right side. First, student SB correlated number 27.9 on the left with number 28 on the right to get 0.1 difference. Furthermore, SB students concluded that number value on the right side was obtained from the result of adding the number on the left side with 0.1 . Thus, to find number that have not been known in the right side, it could be done by summing numbers 41.8 on the left with a number of 0.1 and obtained number 41.9 on the right.

Question 3:

$2400 \times 0,4=\mathrm{c} \times 4$

Determine the value of $c$ !

Answer:

Fig. 3 below is student SB answer to question 3 .

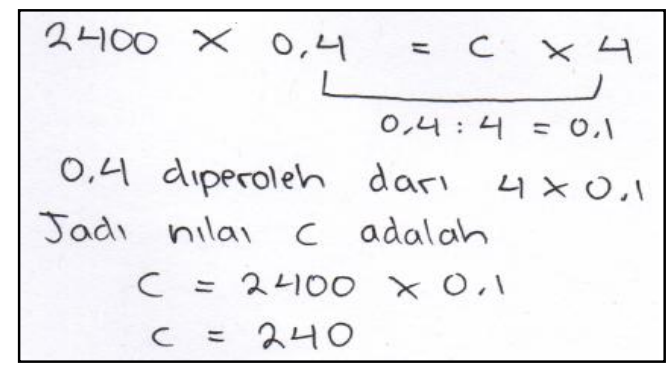

Fig. 3. The student SB answer of question 3

Fig. 3 show that alleged student SB found the connection between numbers on the left side with numbers on the right side. Student SB correlated number 0.4 on the left with the number 4 
on the right side, then calculated the quotient of 0.4: 4 and acquired number 0.1 . For more details, the result of the researcher's interview with the student SB on the first question are listed in Table III below:

TABLE III. RESULT OF INTERVIEW WITH STUDENT SB OF QUESTION 3

\begin{tabular}{|l|l|}
\hline \multicolumn{1}{|c|}{ Code } & \multicolumn{1}{c|}{ Interview Result } \\
\hline R & "Just look at the sheet on you, what is the value of c?" \\
\hline SB1 & "This is mom. The value of a is240." \\
\hline R & "How do you get the value of c?" \\
\hline SB2 & $\begin{array}{l}\text { "That number 0,4 is divided by 4, which is equal with 0.1. It } \\
\text { means that number } 4 \text { is obtain by multiplying number 0.4 with } \\
\text { O.1. Then, to find out the value of c, it can be done by } \\
\text { multiplying number 2400 with 0.1, which then obtained 240. " }\end{array}$ \\
\hline R & $\begin{array}{l}\text { "Why you don't correlate number } 4 \text { on the right side with } \\
\text { number 2400 on the left side?" }\end{array}$ \\
\hline SB3 & $\begin{array}{l}\text { "Because to find the relations between } 0.4 \text { and } 4 \text { is easier } \\
\text { rather that find correlation between number } 4 \text { and } 24000 . "\end{array}$ \\
\hline
\end{tabular}

Based on interview result with student SB, student SB obtained relationship between numbers on the left side with the numbers on the right side. First, student SB correlated number 0.4 on the left side with number 4 on the right to get quotient result which was 0.1 . Furthermore, since number 4 on the right side is obtained from multiplying number 0.4 on the left with 0.1 , student SB concluded that the value of number on the right side is obtained by multiplying number on the left side with 0.1 . So, to find the value of number that is not yet known on the right side, it could be done by multiplying number 2400 on the left side with a number of 0.1 and obtained number 240 on the right.

Question 4:

$12 \div 0,8=\mathrm{d} \div 8$

Determine the value of $d$ !

Answer:

Fig. 4 below is student SB answer to question 4 .

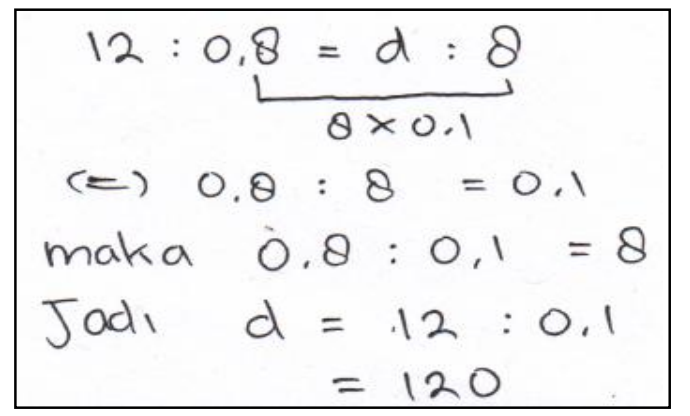

Fig. 4. The student SB answer of question 4

Fig. 4 show that alleged student found connection between numbers on the left side with the numbers on the right side. Student SB correlated the number 0.8 on the left with the number 8 on the right, then calculated the multiplication product of 8 by 0.1 , which was 0.8 . For more details, the result of the researcher's interview with the student SB on the first question are listed in Table IV below:
TABLE IV. RESUlt OF INTERVIEW WITH STUDENT SB OF QUESTION 4

\begin{tabular}{|l|l|}
\hline \multicolumn{1}{|c|}{ Code } & \multicolumn{1}{c|}{ Interview Result } \\
\hline R & "Just look at the sheet on you, what is the value of d?" \\
\hline SB1 & "This is mom. The value of a is 120." \\
\hline R & "How do you get the value of d?" \\
\hline SB2 & $\begin{array}{l}\text { "Number 0,8 on the question is obtained from multiplication } \\
\text { result between number } 8 \text { and 0,1. It same with number } 0,8 \\
\text { divided by 0,1, that resulted number 8." }\end{array}$ \\
\hline R & "Okay, then?" \\
\hline SB3 & $\begin{array}{l}\text { "Nah, because of number } 8 \text { is obtained from dividing number } \\
\text { dividing number } 12 \text { on the left side with } 0,1, \text { thus number } 120 \\
\text { is obtained. }\end{array}$ \\
\hline
\end{tabular}

Based on interview result with student SB, student SB obtained the relationship between numbers on the left side with numbers on the right side. First, student SB correlated number 0.8 on the left side with number 8 on the right side, then obtained the relationship that 0.8 is a multiple of 0.1 as much as 8 times. Furthermore, since the number 8 in the right-hand side is obtained dividing number 0.8 in the left with 0.1 , students SB concluded that the value of number on the right-side number is obtained from dividing number in the left side with 0.1 . Thus, to find the number that is not yet known on the right side, it could be done by dividing number 12 on the left with number of 0.1 and obtained number 120 on the right side.

\section{CONCLUSION}

Based on the analysis of the research result, students have been able to think relationally. When they were asked to look for undetermined values in a mathematical sentence, students do not directly calculate the value on the left and right side. However, students looked for relationships between numbers on the left side with numbers on the right. Furthermore, after students found the relationship of both numbers on the left and right side, without counting, students can find the value of the unknown number. If associated with relational thinking characteristics which are Established Relational Thinking, Consolidating Relational Thinking, and Emerging Relational Thinking [10], thus students could be included in Established Relational Thinking type. This is caused by the ability of students to always specify the relations between number on the left side with the number on the right side, without exception, also finding the difference of the two numbers and use words to describe the relation of the value that being used in the left and right segments correctly.

This study is limited to junior high school students with high capability in mathematics and limited to arithmetic equations. Therefore, it is necessary to study the relational thinking process of junior high school students with low or average capability or senior high school students and using material other than arithmetic equations as instruments.

\section{REFERENCES}

[1] P. Andrews, and J. Sayres, "Teaching linear equations: Case studies from Finland, Flanders and Hungary". Journal of Mathematical Behavior, vol. 31, pp. 476-488, 2012.

[2] S. Aydin, E. S. Celikkol, M. Of, C. Mutlu, "On the two connected concepts in secondary school mathematics: algebraic expressions and 
linear equations". Procedia - Social and Behavioral Sciences, vol. 106, pp. 1966-1970, 2013.

[3] Baiduri, "A Relational Thinking Process of Elementary School Students with High Capability". Journal of Educational and Developmental Psychology, vol. 4, (2), pp. 24-34, 2014.

[4] T. P. Carpenter, L. Levi, M. L. Franke, J. K. Zeringue, "Algebra in Elementary School: Developing Relational Thinking”. ZDM, vol. 37, (1), pp. 53-59, 2005

[5] V. Napaphun, "Relational Thinking: Learning Arithmetic in order to Prmote Algebraic Thinking". Journal of Science and Mathematics, vol. 35, (2), pp. 84-101, 2012.

[6] S. R. Powell, and L. S. Fuchs, "Contribution of Equal-Sign Instruction Beyond Word-Problem Tutoring for Third-Grade Students with Mathematics Difficulty". American Psychological Association, vol. 102, (2), pp. 381-394, 2010.
[7] A. C. Stephens, "Equivalence and Relational Thinking: Preservice Elementary teachers' Awareness of Opportunities and Misconceptions". Journal of Mathematics Teacher Education, vol. 9, pp. 249-278, 2006.

[8] M. Stephens, "Students' Emerging Algebraic Thinking in the Middle School Years". Mathematics Essential Research, Essential Practice, vol. 2, pp. 678-687, 2007.

[9] M. Stephens, and A. Riberio, "Working Towards Algebra: The Importance of Relational Thinking". Revista Latinoamericana de Investigacion en Matematica Educativa, vol. 15, (3), pp. 373-402, 2012.

[10] M. Stephens, amd X. Wang, "Investigating Some Junctures in Relational Thinking: A study of year 6 and Year 7 students from Austalia and China". Journal of mathematics Education, vol. 1, (1), pp. 28-39, 2008.

[11] E. Warren, "The role aristhmetic structure in the transition from arithmetic to algebra. Mathematics Education Research Journal, vol. 15, (2), pp. 122-137, 2003. 